\title{
1. Under the name of Tällberg
}

There will never be the same, always new days and lights. On a summer day everything is blue, the lake, the sky - a blue dreamland with white glitter in all this blue, white clouds, white geese on the lake and a white steamer gliding over the blue surface, white birch trees like straight shining candles ...

(Forslund, 1922, p. 37) ${ }^{1}$

These words convey impressions that are colourfully put together under the name of 'Tällberg', which on a map drawn according to cartographic conventions appears as a Swedish village. When reading the words of Forslund (1922) we are compelled to an interpretation and understanding that give association to an impressionistic painting. We become attuned to the narrator's sense of the shifting blue with white weft threads going through materials that relate us to the sky, earth and water. With reference to Tällberg other materials also get our attention, in various ways colouring inhabitants' descriptions of business activities, constituted of the sociality of human interactions and relations. The descriptions are mediated narratively in the form of stories that help advancing our understanding of family business as an emergent phenomenon. 'Family business' dissolves into activities with which people are entwined, immersed in materials spatially extended.

In complement to existing family business research the book suggests an alternative approach, a theory of socio-material weaving that purports narrative information in the form of stories to be conducive to an understanding of family business as activities engaged with materials related to spatiality. The theory development process is stimulated by Tällberg place materials and a problematization that highlights the need to add to existing family business research a spatial-material dimension with a concern for the hermeneutic-phenomenological idea that we are beings-in-the-world, intimately involved with the world with others with materials. As pointed out in the book, the social gains considerable attention from family business scholars with little discussion of the spatial material.

Since the notion of place is closely related to space, the theory is also concerned with space, clearly differentiating between space and place. 
The 'weaving' activity included in the suggested theory implies bringing together the sociality of activities with the material, illustrating that materials are appropriated in activities in the promotion of existential space, and experientially explored in a bodily lived sense in relation to place. Informed by the philosophical tradition of hermeneutic phenomenology a theory of socio-material weaving presumes interpretation and understanding, occurring as stories evolve in between the storytellers and the researcher, interlaced with insights drawn from existing theories of family business, social and material, space and place. Tentative in character, the theory aims for plausibility, rather than testability, validity and generalizability, laying out lines that can be followed in subsequent theory construction (cf. Stewart et al., 2010; Weick, 1989).

The family business is everywhere. Family business constitutes one of the fastest growing research areas today. Students and scholars from all over the world study the topic of family business. An approach that theorizes family business as socio-material weaving could inspire interpretation and understanding that extend beyond a view that insists on conceiving of family business as a predefined context that relates to the wider context of an external environment. In terms of 'good theory' it aims for newness and usefulness (Shephard \& Suddaby, 2017; Weick, 1989), opening up avenues of research that bring together the social and the material in an account of a spatial-related material dimension. It draws on stories that tell about people's entwinement with a variety of business activities, sorrows encumbered and challenges faced, and these stories could also be of interest to practitioners, providing relevance for 'practice-present and future' (Corley \& Gioia, 2011, p. 26) increasing the awareness that activities extend through materials.

\section{STIMULATING THEORY BUILDING}

Geographically, Tällberg describes a piece of a Swedish landscape, a spatial expanse labelled "village'" with 200 inhabitants and eight hotels beautifully located on the slope down to Lake Siljan in the province of Dalarna, during the Middle Ages the most populous province in Sweden. Lake Siljan was created 377 million years ago when a meteorite crashed into the earth. A giant lump of space rock formed a ring-shaped crater estimated to have had a diameter of 40 kilometres and a depth of five kilometres (Dalarna, 2016).

Old photos, tourist brochures and books produced by the Tällberg inhabitants themselves render a history that goes back to the mid-1400s 
when the name Thaellebaerghe, which means 'Mountain of Pine Trees', was used. Back then people involved in farming, kept cattle and cultivated a piece of land for their own livelihood. In the early 1900s, the railroad was built, making a larger geographical area accessible. Trails were laid that made it possible for people to travel more than 1200 kilometres, all the way from Stockholm via the village of Tällberg to the town of Kiruna in Lappland, the northernmost province in Sweden. The train was called 'Dollar-train'. With the growing number of tourist arrivals in Tällberg new opportunities for earning money were constructed and as a result, some farmhouses were converted into hotels. The Dollar-train made a stop in Tällberg where buses took the passengers to the hotels. The development of the railroad helped to push farming families into changing their ways of living, gradually decreasing the involvement in farming activities and increasingly engaging in hotel business activities (Tällbergs Byalag, 2007). Activities were also oriented towards guest home lodging and eduction (Alm, 1969).

The book presents five stories that direct attention to business activities in association with hotels, a guest home and a school, constituted of human interactions and relations, interwoven with materials that relate to the Tällberg place and other materials drawn into and used with activities. Under the name of Tällberg we catch a glimpse of a dynamic transformative field of material relations where family businesses dissolve into activities.

\section{EXISTING FAMILY BUSINESS RESEARCH: LITTLE CONCERN FOR THE MATERIAL}

Family business constitutes one of the fastest growing research areas today with students and scholars from around the world covering a wide range of themes. A review of more than 450 articles published over the past three decades in top journals displays that the six most important themes of family business research are the management of the firm, performance and growth, characteristics and attributes, interpersonal family dynamics, governance, and succession (Evert et al., 2016). The social dimension of family business receives much interest in this research (Chapter 2). Studies incorporate analyses of human interactions and relations, highlighting socioemotional wealth, familiness, stewardship and cultural competence, for example. A material dimension associated with space and place is to a large extent left out from scholarly discussions of the social. 
Family business, common derivatives of which are family enterprise, family firm and family company, is most often treated as an open system consisting of family and business reciprocally related to each other (Zahra \& Sharma, 2004), figuratively modelled by two intersecting circles (Lansberg, 1983). 'The family system influences the business system through different formal and informal mechanisms', explains Mazzelli (2015, p. 40). Family business signifies 'a type of organization that is intentionally formed as a combination of two otherwise separate social categories' (Whetten et al., 2014, p. 480) and often entails an instrumental use of culture and values (cf. Sorenson, 2014). The extent and nature of the family's involvement in the business are in some studies measured by scaling techniques focused on culture and values (Astrachan et al., 2002; García-Alvarez \& López-Sintas, 2001; Klein et al., 2005).

It is argued that the co-evolvement of family and business suggests a 'truly realistic' approach to understanding family business (Neubauer, 2003 , p. 269), a realism that also serves as the basis of the three-circle model which comprises the subsystems of family, business and ownership (Gersick et al., 1997; Tagiuri \& Davis, 1996) and gives culture the role of an integrating mechanism for the three subsystems (Fletcher et al., 2012). Through what is termed 'bulleye' another subsystem is added, that of management (Pieper \& Klein, 2007). The bulleye emphasizes the open system features as regards feedback loops and reciprocal relationships between the subsystems and between the whole system and the external environment (cf. Rautiainen et al., 2012). The family business system is affected by external and internal environmental conditions and depending on the flexibility of the management of this system, a 'fit' is achieved between the external and the internal (cf. Kammerlander et al., 2015). 'The core rational is that flexibility enables adaptability to the changing internal and external environment', assert Sharma and Salvato (2013, p. 37). The family firm is a bounded social entity that interacts with the wider external context (Martinez \& Aldrich, 2014).

The family business, accordingly, is attributed an inside and an outside, a description that prioritizes relationships between the subsystems that make up the whole. In line with this prioritizing, the 'components-of-involvement' and the 'essence' definitional approaches differentiate family business as a unique entity readily available for study. The former approach focuses on the family's involvement in ownership, management or governance of the business and on who the family members are, and the latter on behavioural distinctiveness of the family business (Sharma \& Salvato, 2013). 
Indeed, there are many ways of defining family business. 'Regardless of the family business definition utilized, one consistent issue arises. Family businesses are owned and/or operative by a group of individuals who are family', inform Ring et al. (2017, p. 160). Family business is a business in which a family has a share of ownership and voting rights that allow substantial influence in terms of control and management of the business (Neubauer, 2003).

Apparently the systems view introduces family business as a finalized entity (Helin, 2011) with little attention paid to how the social interweaves with the material with a concern for spatiality.

\section{WITH A CONCERN FOR THE MATERIAL}

While family business research has largely disregarded materials, organizational research has shown a growing interest in the material (e.g. Dameron et al., 2015; Jarzabkowski \& Kaplan, 2015; Werle \& Seidl, 2015). Lê and Spee (2015) present four materiality approaches employed in organizational studies: communication; technology; sensemaking; positivism. The communication approach focuses on verbal, non-verbal and written text materials through which the organization is achieved, and on textual objects, physical locations of work and body - materiality relations. The technology approach incorporates the concept of sociomateriality, introduced by Orlikowski (2007), and directs attention to the relationships between technology, organization and people. The emerging sociomateriality theme in practice-based strategy research informs us that the social transpires through materials such as PowerPoint, cardboard cube, whiteboard and post-it notes, and through spatial arrangements, financial security and emotions (Balogun et al., 2014; Beech \& Johnson, 2005; Cooren et al., 2015; Kaplan, 2011; Lê \& Spee, 2015). Material agency is disclosed by strategy texts, affecting strategic planning through communicating meaning, guiding, disciplining and structuring discussions (Kaplan, 2011; Spee \& Jarzabkowski, 2011; Vaara et al., 2010).

The sensemaking approach accounts for links between material and cognition, assuming that knowledge is embedded in materials that contain memory traces. Further, the approach examines how material interacts with interpretative processes and is used to drive behaviour. The positivist approach attends to materials defined by their physical qualities. It focuses on how materials influence and are influenced by human emotion, cognition and behaviour. Neuroscience methods are also 
employed by this approach to analyse underlying brain processes (Lê \& Spee, 2015).

The materiality approaches raise our awareness of the importance of addressing the material in an organizational space. As Lê and Spee (2015, p. 582) highlight, 'spatial and material aspects are fundamental to accomplishing any organizational activity and process'. When elaborating on those aspects we must also make clear that material cannot be equated with materiality. The term 'material' derives from the Latin mater which means 'mother'; materials are 'the stuff that things are made of' and have nothing to do with materiality (Ingold, 2011, p. 20). Hodges (1976) provides us with rich information of material stuff such as wood, clay, stone, glass, leather, wool, copper, gold and silver and describes the processes that bring the flesh and blood of our bodies into corporeal contact with the material. For example, working with wood materials, felling trees, thinning out, cutting branches and if large enough using them as timber, involve the human body. By drawing on insights from Heidegger's (1962) hermeneutic-phenomenological work we are able to advance our understanding of the material and the spatial aspect in an existential meaning, accounting for a being of the timber material in its usability as expressed by a readiness-to-hand for house construction. From a Heideggerian view, materials are worked with and made use of in practice, attributed the character of tools (or equipment) which suggests describing socio-material practices as,

open-ended human activities transpiring within material arrangements, unfolding in time and carried out by skilful agents whose actions are based on: tacit understandings, explicit rules and teleo-affective structures; the bodily coordination and orientation of an agent to the task at hand; and the incorporation of tools within the field of an agent's bodily comportment. (Tsoukas, 2015, pp. 62-3)

Heidegger's (1962) hermeneutic-phenomenological work helps us in problematizing the relationship between the material and the social through an approach that interweaves the social and the material with a concern for existential spatiality (Lamprou, 2017). As pointed out in this book, wood and other materials such as glass and stone, which each could be analysed for its physical properties, engage with business activities focused on maintenance and reconstruction, renewal and development of buildings and land. Materials are worked with, caught up in activities, in bodily doings used as tools for the performance and extension of activities in which family members and others find themselves. 
Existential space is implied in the extension of activities. Materials are not, once and for all, fixed things that can be objectively identified by specific attributes, but bound up in business activities with which people entwine.

Activities also take place (Seamon, 2018). In appreciation of Heidegger's (1962) philosophy, geographical and anthropological studies have broadened the focus to include landscape in connection to 'place', addressing a bodily lived aspect of place (e.g. Casey, 2001; Ingold, 2011). Place describes a piece of land scaped by people, 'a textured composite' of materials grown and made (Ingold, 2011, p. 130). Under the name of Tällberg, place refers to a scaped land where present future-oriented business activities with which people are entwined recall past activities, reminding us of people not living any longer, their bodily doings and the paths made. Business activities are not performed within a geographical context and place-bound but place-binding through paths people have trailed and are trailing (Ingold, 2011).

Business activity is a dimension of practice and of a sociality that in Schatzki's (1996) terms denotes a vast Zusammenhang of lives, a hanging-togetherness (cf. Ericson, 2014), which involves genuinely related individuals.

\section{INVOLVING GENUINELY RELATED INDIVIDUALS}

Etymologically, 'social' stems from Latin socialis, which refers to companionship, allies, united and living together (Etymology Dictionary, 2020), examples of a hanging-togetherness to which can be added kinship. By definition, kinship is 'the network of genealogical relationships and social ties modelled on the relations of genealogical parenthood' (Holy, 1996, p. 40). Kinship directs us to 'family', a term that originally comes from Latin familia and the closely related term famulus, which means 'slave' (Etymology Dictionary, 2020). As Herlihy (1991, p. 3) informs: "In classical Latin literature under the name of "family", there appear prostitutes in a brothel; publicans or tax collectors, moneyers; military units; schools of philosophers; and, in Christian usage, demons, monks, and the clergy generally.'

In medieval literature the notion of family conveyed an authoritarian structure as presented by a hierarchical order with a large group of people placed under the authority of a single person. Family was also presented as a domestic unity based on three sets of relationships, lord to servant, 
husband to wife, and father to child. When the paternal authority weakened, a domestic form emerged that allowed affection with love and caritas (Latin for charity) to be expressed. Herlihy (1991, pp. 10-11) summarizes: 'In this view, our love for these joined to us by blood relationships was founded on nature and was therefore stable and durable; in contrast, our love for those unrelated to us was based on convention and was unstable and shifting.'

More recent portrayals of family include a married heterosexual couple and children, the so-called nuclear family, and in a wider sense, a life process of collaborative engagement, emotional bonding and a joint building of a shared reality, discourse, and institution (Hall, 2003). 'Family' denotes a form of living together that emerges through genuine relationships based on blood and marriage. 'Genuine' also refers to durable relationships established between friends and are characterized by emotional bonding, 'reciprocity, mutual dependence and trust' (Hall, 2003 , p. 33). The quality of genuine is not necessarily confined to interpersonal relationships between members of a family but includes also particular well-known others such as friends, Sjöstrand (1997) explains.

Akin to genuine, and aligned with the extended family dimension, affinal kin focuses on 'the emotional kinship groups, which could be connected through descent or marriage and not purely genetics', Akhter (2015, p. 179) points out. The stories presented in this book involve individuals whose relationships are based on blood and marriage and cultivated on the basis of closeness and long-term interaction. It is important to add that these genuinely related individuals are beings-in-the-world, entwined with business activities in amongst materials spatially constituted and extended.

\section{LISTENING TO STORIES}

On the basis of a being-in-the-world narrative methodology, developed from Ricoeur's (1992) conception of narrative and Heidegger's (1962) conception of Dasein (Chapter 4), interpretation and understanding of 'family business' as activities are generated. A precise point of departure based on a definition of family business that treats family and business as distinct systems then is not of relevance to specify in advance. We come to an understanding of the social and the material and their interwovenness when listening to people's stories about business activities. Five stories evolve through the layering of voices belonging to family members and others, dissolving family-owned hotels, a guest home 
and a school, and owner and manager positions, into activities caught up in spatially related materials. The alternative approach - a theory of socio-material weaving - draws on people's stories about their activities and materials used as tools in an existential sense, and experienced in a bodily lived sense.

\section{REMAINING CHAPTERS}

Chapter 2 acknowledges that existing family business research directs considerable attention to the social dimension with reference to socioemotional wealth, familiness, emotions, stewardship, cultural competence and entrepreneurship, for example. With succession in focus the social complexity of trans-generational change is explored. Without a concern for socio-material weaving scholars commonly refer to family business as a context attributed the characteristics of a system. The resource-based view and theories of social exchange, structural functionalism, symbolic interactionism, agency and evolution and a combination of theories explain what happens within the family business system and how it affects and is affected by the external environment. 'External environment' suggests the wider spatial context of industrial district, region and country in which scholars place the family business. Also noted, in business history research we are encountered with family businesses that operate and develop in continental, international and country-specific contexts.

Chapter 3 refers to the re-materializing of organizational life that is taking place in organization and management research, presenting three approaches: space as distance; space as materialization of power relations; space as lived experience. Integrated, these approaches account for scale of space in terms of micro, meso and macro levels. The chapter also points to a need for reflection on the ontological constitution of the social, and on the material in relation to spatiality, arguing that the philosophical tradition of hermeneutic phenomenology as represented by Heidegger $(1962,1971)$ provides concepts that could aid our understanding of spatiality. With reference to 'spatiality as care' it is acknowledged that material as being-things constitutes 'equipmentality', assigned theoretical and practical significance in human activity they contribute existential space. With reference to geographical and anthropological work informed by hermeneutic-phenomenological philosophy, 'place' is discussed in a bodily lived sense. 
Chapter 4 focuses on narrative and story, placing a language-using storytelling human being, homo narrans, in the centre. Under the hermeneutic-phenomenological assumption of pre-narrative engagement in the world it suggests a being-in-the-world narrative methodology. As pointed out, intelligibility of being-in-the world expresses itself as discourse, language broken up in words constitutive of stories. The suggested methodology implies understanding and interpretation and allows for different temporal orientations and multiple plots to play out. The chapter also includes a description of how empirical-oriented information has been generated and how stories emerge through the involvement of individuals representing four families, emphasizing that the researcher is not an interviewer or observer, rather a 'story partner'. In between actualities and possibilities and with an account for what has been, stories emerge multivoicedly as voices of the living, the not living and the voice of the researcher blend.

Chapter 5 presents three stories in close relation to each other. The Siljanstrand and the Green Hotel story concentrate interest to first-generation activities and to the acquisition of a 'glittering jewel' and the realization of a 'San Michele dream'. The stories indicate that 'ownership' of Siljanstrand and Green Hotel unfolds owning activities with much attention focused on renewal and development of buildings and land. The Siljansgården story refers to a Tällberg land with grass fields, juniper and rose bushes and birch trees. It includes a three-generation family's involvement in activities oriented towards sports and recreation, education and guest home lodging. The activities open up to the social and the material, interwoven in the present with past activities recalled and a future imagined, highlighting a cultural achievement, a holistic treatment of body and soul, a 'co-worker for Life' and a beautiful Tällberg.

Chapter 6 presents the Klockargården story with reference to the five-generation Sandberg family. As exhibited, members representing the second, third and fourth generation have been intensely involved in business activities related to handicraft, sheep farming, textile education, guest home, hotel lodging, conferences and entertainment. The story tells that activities extend through materials associated with timbered buildings, many of which were bought, dismantled, moved from other places in Dalarna and rebuilt on the Klockargården land. Particular importance is ascribed the material of timber, which brings 'Nature' along, together with business activities constitutive of a nature-business wholeness. The chapter also refers to sorrows encumbered. It further acknowledges that 
Klockargården has been sold and that the Sandberg family presently engages in the development of a project with business activities making land material available for presumptive buyers who wish to build a home in Tällberg and enjoy a beautiful view of Lake Siljan.

Chapter 7 presents the Åkerblads-Tällbergsgården story with reference to the 22-generation Åkerblad family. It illustrates Tällbergsgården hotel business activities in close relation to and as an extension of Åkerblads hotel business activities. Keeping alive the history of earlier generations of the Åkerblad family is a leitmotif applied throughout present future-oriented hotel business activities and is emphasized by the expression: 'the future is in history'. The story makes us aware that family members in their present entwinement with hotel business activities follow and connect with paths made by people not living any longer. A past unfolds in, between, through and around the old houses, cottages and härbren, ${ }^{3}$ reminding us of earlier generations' engagement in farming activities. Owning and managing activities direct attention to maintenance and reconstruction, architectural and interior design that make use of materials such as timber, birch logs, glass, fine-grained metamorphic rock and candle wax.

Chapter 8 refers to the Siljanstrand, Siljansgården, Green Hotel, Klockargården and the Åkerblads-Tällbergsgården stories, directing attention to business activities caught up in materials that relate to spatiality as expressed by existential space and bodily lived place. From a hermeneutic-phenomenological perspective family business dissolves into activities with which people entwine in amongst materials. As pointed out, hermeneutic-phenomenological interpretation and understanding of the social and the spatial material shifts the focus away from entitized conceptions of family business contexts to 'entity' in the constitution of entity-ness accountable for existence and being. The chapter underlines the importance of adding to the study of family business, an alternative approach, in the form of a theory of socio-material weaving sensitive to a way of being in the world that implies an individual's entwinement with activity. In the discussion of the development of a socio-material weaving theory plausibility and a narrative truth are emphasized. 


\section{NOTES}

1. Also in Tällbergs Byalag (2007, p. 8). My translation.

2. By definition, village is a group of houses usually located in the countryside (Cambridge English Dictionary, 2020).

3. A härbre is a small timbered storehouse. 